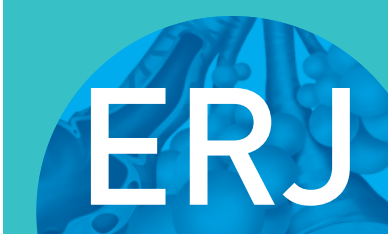

open research
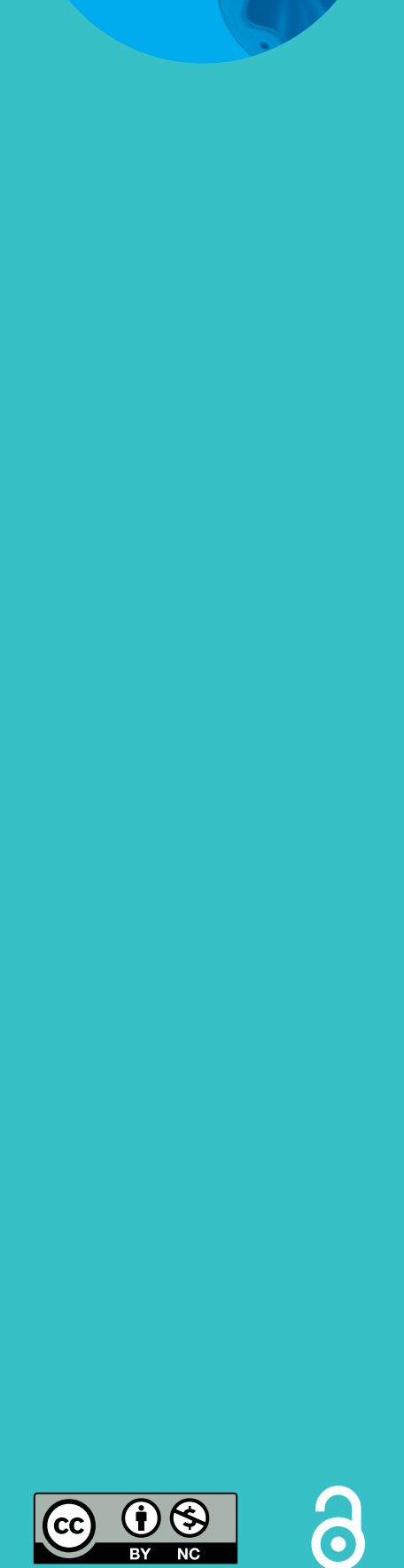

\title{
Persistent symptoms 3 months after a SARS-CoV-2 infection: the post-COVID-19 syndrome?
}

\author{
Yvonne M.J. Goërtz 1,2,3,9, Maarten Van Herck 1,2,3,4,9, Jeannet M. Delbressine ${ }^{1}$, \\ Anouk W. Vaes (10) ${ }^{1}$, Roy Meys ${ }^{1,2,3}$, Felipe V.C. Machado ${ }^{1,2,3}$, Sarah Houben-Wilke', \\ Chris Burtin ${ }^{4}$, Rein Posthuma (1) ${ }^{1,2,3}$, Frits M.E. Franssen (10) ${ }^{1,2,3}$, \\ Nicole van Loon ${ }^{1,5}$, Bita Hajian ${ }^{1,2,3}$, Yvonne Spies ${ }^{6}$, Herman Vijlbrief 6 , \\ Alex J. van 't Hul (10 ${ }^{7}$, Daisy J.A. Janssen (10 ${ }^{1,8}$ and Martijn A. Spruit (10) $1,2,3,4$
}

\section{ABSTRACT}

Background: Many patients with COVID-19 did not require hospitalisation, nor underwent COVID-19 testing. There is anecdotal evidence that patients with "mild" COVID-19 may complain about persistent symptoms, even weeks after the infection. This suggests that symptoms during the infection may not resolve spontaneously. The objective of this study was to assess whether multiple relevant symptoms recover following the onset of symptoms in hospitalised and nonhospitalised patients with COVID-19.

Methods: A total of 2113 members of two Facebook groups for coronavirus patients with persistent complaints in the Netherlands and Belgium, and from a panel of people who registered on a website of the Lung Foundation Netherlands, were assessed for demographics, pre-existing comorbidities, health status, date of symptoms onset, COVID-19 diagnosis, healthcare utilisation, and the presence of 29 symptoms at the time of the onset of symptoms (retrospectively) and at follow-up (mean \pm sD $79 \pm 17$ days after symptoms onset).

Results: Overall, 112 hospitalised patients and 2001 nonhospitalised patients (confirmed COVID-19, $\mathrm{n}=345$; symptom-based COVID-19, $\mathrm{n}=882$; and suspected COVID-19, $\mathrm{n}=774$ ) were analysed. The median number of symptoms during the infection reduced significantly over time (median (interquartile range) 14 (11-17) versus $6(4-9) ; \mathrm{p}<0.001)$. Fatigue and dyspnoea were the most prevalent symptoms during the infection and at follow-up (fatigue: $95 \%$ versus $87 \%$; dyspnoea: $90 \%$ versus $71 \%$ ).

Conclusion: In previously hospitalised and nonhospitalised patients with confirmed or suspected COVID19, multiple symptoms are present about 3 months after symptoms onset. This suggests the presence of a "post-COVID-19 syndrome" and highlights the unmet healthcare needs in a subgroup of patients with "mild" or "severe" COVID-19.

@ERSpublications

Previously hospitalised and nonhospitalised \#COVID19 patients can still have multiple persistent symptoms 3 months after the onset of infection-related symptoms. This provides the first evidence for a "post-COVID-19 syndrome" \#longCOVID https://bit.ly/3h8iJ80

Cite this article as: Goërtz YMJ, Van Herck M, Delbressine JM, et al. Persistent symptoms 3 months after a SARS-CoV-2 infection: the post-COVID-19 syndrome?. ERJ Open Res 2020; 6: 00542-2020 [https://doi.org/10.1183/23120541.00542-2020].

\footnotetext{
This study is registered at www.trialregister.nl with trial number NTR NL8705
}

Data availability: The datasets generated during and/or analysed during the current study are available from the corresponding author on reasonable request.

Received: 30 July 2020 | Accepted after revision: 13 Aug 2020

Copyright $\odot$ ERS 2020. This article is open access and distributed under the terms of the Creative Commons Attribution Non-Commercial Licence 4.0. 


\section{Introduction}

Over recent months, severe acute respiratory syndrome coronavirus-2 (SARS-CoV-2) infection has been confirmed in millions of people around the world [1], resulting in hospitalisation in thousands of cases. Multiple symptoms like fever, cough, fatigue, dyspnoea, headache, diarrhoea, nausea and vomiting, have been reported during the hospital stay $[2,3]$. About 60 days after onset of the first COVID-19 symptom, only $13 \%$ of the previously hospitalised COVID-19 patients were completely free of any COVID-19-related symptom, while $32 \%$ had one or two symptoms and $55 \%$ had three or more [4].

Next to the hospitalised patients with "severe" coronavirus disease 2019 (COVID-19), millions of people have most probably been infected with SARS-CoV-2 without formal COVID-19 testing and/or medical treatment in the hospital $[5,6]$. Indeed, COVID-19 testing capacity was not available for patients who initially were considered to have mild signs and symptoms. These patients are classified as having "mild" COVID-19 as they only require home care and the infection is expected to resolve [7, 8]. Then again, patients with the so-called "mild" COVID-19 may still complain about persistent symptoms, even weeks after the onset of symptoms. To date, however, only anecdotal evidence is available [9, 10].

This study assessed whether or not multiple relevant symptoms recover following the onset of symptoms in hospitalised and nonhospitalised patients with COVID-19.

\section{Methods}

Study design and participants

Between 4-11 June 2020, members of two Facebook groups for coronavirus patients with persistent complaints in the Netherlands ( 11000 members; "Corona ervaringen en langdurige klachten!") [11] and Flanders (Belgium, 1200 members; "Corona patiënten met langdurige klachten (Vlaanderen)") [12] and a panel of $\sim 1200$ people who registered at a website of the Lung Foundation Netherlands (www. coronalongplein.nl) for additional information on coronavirus were invited to complete an online survey. The medical ethics committee of Maastricht University stated that the Medical Research Involving Human Subjects Act does not apply for this study and that an official approval of this study by the committee was not required (METC2020-1978). The Medical Ethics Committee of Hasselt University formally judged and also approved the study (MEC2020/041). All respondents gave digital informed consent at the start of the questionnaire. Without the informed consent, the remaining questionnaire could not be completed.

\section{Measures}

Besides some general questions about demographics, pre-existing comorbidities, self-reported health status (good/moderate/poor) before the onset of symptoms as well as at follow-up (i.e. at the time of completing the questionnaires), date of onset of symptoms, and COVID-19 diagnosis (please see below), healthcare utilisation during/after the infection (e.g. general practitioner/physiotherapist/medical specialist/ psychologist/dietician/nurse/occupational therapist), respondents were asked about the presence (yes/no) of symptoms at the time of infection (retrospectively) and at the time of completing the questionnaires ("symptoms at follow-up"). Scientists (with a background in rehabilitation sciences, psychology, sociology and pulmonology), methodologists, healthcare professionals (elderly care specialists, pulmonologists) and patients with COVID-19 from the two Facebook groups were closely involved in putting together the list of 29 symptoms that were studied $[2,3,13,14]$ : increased body temperature $\left(37.0-37.9^{\circ} \mathrm{C}\right)$, fever (body temperature $\geqslant 38.0^{\circ} \mathrm{C}$ ), cough, mucus, nose cold, sneezing, dyspnoea, sore throat, fatigue, muscle pain, joint pain, anosmia, ageusia, headache, dizziness, diarrhoea, nausea, vomiting, red spots on toes/feet, pain/ burning feeling in the lungs, ear pain, chest tightness, pain between shoulder blades, heart palpitations, increased resting heart rate, eye problems, sudden loss of body weight, burning feeling in the trachea, and hot flushes. Moreover, there was the option of an open-text field to add other symptoms. These data contained many different symptoms, including loss of concentration and cognitive function, chills, rashes and sleeping problems. However, these "other" symptoms were not analysed in detail due the large

Affiliations: ${ }^{1}$ Dept of Research and Development, Ciro, Horn, the Netherlands. ${ }^{2}$ Nutrim School of Nutrition and Translational Research in Metabolism. Maastricht, the Netherlands. ${ }^{3}$ Dept of Respiratory Medicine, Maastricht University Medical Centre (MUMC+). Maastricht, the Netherlands. ${ }^{4}$ REVAL - Rehabilitation Research Center, BIOMED - Biomedical Research Institute, Faculty of Rehabilitation Sciences, Hasselt University, Diepenbeek, Belgium. ${ }^{5}$ Dept of Internal Medicine, MUMC+, Maastricht, the Netherlands. ${ }^{6}$ Lung Foundation Netherlands, Amersfoort, the Netherlands. ${ }^{7}$ Dept of Pulmonary Disease, Radboud University Medical Center, Nijmegen, the Netherlands. ${ }^{8}$ Dept of Health Services Research, Care and Public Health Research Institute, Faculty of Health, Medicine and Life Sciences, Maastricht University, Maastricht, the Netherlands. ${ }^{9}$ These authors contributed equally.

Correspondence: Yvonne M.J. Goërtz, Dept of Research and Development, Ciro, Hornerheide 1, 6085 NM Horn, The Netherlands. E-mail: yvonnegoertzQciro-horn.nl 
heterogeneity. The proportion of patients selecting "yes" per symptom was calculated, including "other" if selected. The whole sample was analysed. Moreover, patients were analysed after stratification in four groups: 1) hospitalised with confirmed COVID-19 (regular ward, no admission to intensive care unit (ICU)); 2) nonhospitalised with confirmed COVID-19 (based on reverse transcriptase PCR (RT-PCR) test and/or computed tomography scan of the thorax); 3) nonhospitalised with symptom-based COVID-19 (based on symptoms by doctor, no formal COVID-19 testing); and 4) nonhospitalised with suspected COVID-19 (no COVID-19 testing, no symptom-based diagnosis by doctor).

\section{Statistical analysis}

Statistical analyses and visualisation were conducted using SPSS v25.0 (IBM Corp., Armonk, NY, USA), Graphpad Prism 8.3.5. (GraphPad Software, La Jolla, CA, USA), and SankeyMATIC (http://sankeymatic. $\mathrm{com} /$ build/). Data were presented as mean $\pm \mathrm{SD}$, median and interquartile range or frequency and proportion, as appropriate. Between-group analyses were performed with the Chi-squared test or Kruskal-Wallis $\mathrm{H}$ test. Differences within groups were evaluated with the Wilcoxon signed-rank test. Subsequently, post hoc analyses were performed with a Bonferroni correction for multiple comparisons. Multiple regression analysis was performed to predict the number of symptoms at follow-up from age, self-reported health status before the onset of symptoms, self-reported pre-existing comorbidities and number of symptoms during the infection. A priori, the level of significance was set at 0.05 .

\section{Results}

\section{Demographic and clinical characteristics}

In total, 2159 people responded to the online questionnaire (estimated response rate: 16\%). Respondents who were admitted to ICU $(n=15)$ were excluded from the analyses. Additionally, 31 respondents were removed before the start of the analyses due to missing data (e.g. sex not reported or not willing to report, $\mathrm{n}=9$ ), an onset of symptoms before 1 January, 2020 (the first official confirmed case of COVID-19 in the Netherlands was on 28 February, 2020 and in Belgium on 4 February, 2020, n=8), or reporting that the onset of symptoms was less than 3 weeks ago $(n=14)$. Finally, the data of 2113 respondents ( $85 \%$ women, median age: 47 (39-54) years, median body mass index (BMI): $25(23-29) \mathrm{kg} \cdot \mathrm{m}^{-2}$ ) were used for further analyses.

Overall 112 patients were previously hospitalised, and 2001 were nonhospitalised (confirmed COVID-19, $\mathrm{n}=345$; symptom-based COVID-19, $\mathrm{n}=882$; and suspected COVID-19, $\mathrm{n}=774$ ). Table 1 summarises the clinical characteristics of the whole sample and of the four groups. The proportion of women and the proportion of patients without pre-existing comorbidities were lower in the hospitalised sample, which was older and had a higher BMI compared to the three nonhospitalised groups. Furthermore, a significantly higher proportion of hospitalised patients received care by a medical specialist, physiotherapist, psychologist, dietician and nurse.

\section{Symptoms during the infection}

Patients reported a median number of 14 (11-17) symptoms, and 97\% of the respondents had $>5$ symptoms (figure 1). The difference in median number of symptoms per subgroup was small but significant, being highest in nonhospitalised patients with a symptom-based diagnosis (table 2). Fatigue (94.9\%) and dyspnoea (89.5\%) were by far the most prevalent symptoms in all the four groups.

\section{Symptoms at follow-up}

Following a mean period of $79 \pm 17$ days (the time between the onset of the first symptoms and completing the questionnaire), the number of symptoms reduced significantly. Indeed, there was a median change of $-7(-10$ to -4$)$ symptoms per respondent $(p<0.001$; figure 1$)$. The difference in median change of symptoms per subgroup was small but significant, being the highest in nonhospitalised patients with confirmed COVID-19 compared to hospitalised, nonhospitalised symptom-based COVID-19 and nonhospitalised suspected-based COVID-19 diagnosis (respectively -7 ( -10 to -5 ) versus -7 ( -9 to -5 ), $-7(-10$ to -4$)$, and $-6(-9$ to -4$) ; \mathrm{p}<0.001)$. Still, fatigue and dyspnoea were the two most prevalent symptoms (figure 2); only $0.7 \%$ of the respondents were symptom-free 79 days after the infection; and $2 \%$ of the respondents had an increase compared to the number of symptoms during the infection (figure 1). Moreover, self-reported health status at follow-up was significantly worse compared to before the infection $(p<0.001$; figure 3$)$. The multiple regression model including age, self-reported health status before the onset of symptoms, self-reported pre-existing comorbidities and the number of symptoms during the infection, statistically significantly predicted the number of symptoms at follow-up $F(4,2108)=293.818$, $\mathrm{p}<0.001$ (adjusted $\mathrm{R}^{2}=0.357$ ). Of the independent variables, the number of symptoms during the infection was responsible for the largest unique contribution $(\beta=0.58, \mathrm{p}<0.001)$. 
TABLE 1 Clinical characteristics of the whole sample and stratified for COVID-19 diagnosis

\begin{tabular}{|c|c|c|c|c|c|c|}
\hline & $\begin{array}{l}\text { Whole sample } \\
\qquad(n=2113)\end{array}$ & $\begin{array}{l}\text { Hospitalised } \\
\text { (n=112] }\end{array}$ & $\begin{array}{l}\text { Nonhospitalised (confirmed } \\
\text { COVID-19) }(n=345)\end{array}$ & $\begin{array}{c}\text { Nonhospitalised (symptom-based } \\
\text { COVID-19) }(n=882)\end{array}$ & $\begin{array}{l}\text { Nonhospitalised (suspected } \\
\text { COVID-19) (n=774) }\end{array}$ & p-value \\
\hline Women & 1803 (85.3) & $78(69.6)$ & 314 (91.0) & 774 (87.8) & 637 (82.3) & $<0.001$ \\
\hline Age years & $47.0(39.0-54.0)$ & $53.0(46.3-60.0)$ & $47.0(37.0-53.5)$ & $46.0(38.0-53.0)$ & $47.0(39.0-54.0)$ & $<0.001$ \\
\hline BMI $\mathrm{kg} \cdot \mathrm{m}^{-2}$ & $25.2(22.6-28.8)$ & $26.9(24.5-30.9)$ & $26.0(23.2-29.4)$ & $25.0(22.3-28.7)$ & $24.9(22.5-28.4)$ & $<0.001$ \\
\hline \multicolumn{7}{|c|}{ Self-reported pre-existing comorbidities } \\
\hline None & $1293(61.2)$ & $51(45.5)$ & 225 (65.2) & 523 (59.3) & $494(63.8)$ & 0.007 \\
\hline 1 comorbidity & $541(25.6)$ & 40 (35.7) & 77 (22.3) & $240(27.2)$ & $184(23.8)$ & \\
\hline $\begin{array}{l}\geqslant 2 \\
\text { comorbidities }\end{array}$ & $279(13.2)$ & $21(18.8)$ & $43(12.5)$ & $119(13.5)$ & $96(12.4)$ & \\
\hline \multicolumn{7}{|c|}{ Self-reported health status before the onset of symptoms } \\
\hline Good & $1799(85.1)$ & $88(78.6)$ & $316(91.6)$ & 743 (84.2) & 652 (84.2) & 0.011 \\
\hline Moderate & $301(14.2)$ & $23(20.5)$ & $27(7.8)$ & $134(15.2)$ & $117(15.1)$ & \\
\hline Poor & $13(0.6)$ & $1(0.9)$ & $2(0.6)$ & $5(0.6)$ & $5(0.6)$ & \\
\hline \multicolumn{7}{|c|}{ Received health care during/after the onset of symptoms } \\
\hline $\begin{array}{l}\text { General } \\
\text { practitioner }\end{array}$ & $1285(60.8)$ & $62(55.4)$ & $191(55.4)$ & $584(66.2)$ & 448 (57.9) & $<0.001$ \\
\hline Physiotherapist & $432(20.4)$ & 42 (37.5) & $74(21.4)$ & 214 (24.3) & 102 (13.2) & $<0.001$ \\
\hline $\begin{array}{l}\text { Medical } \\
\text { specialist }\end{array}$ & $366(17.3)$ & $49(43.8)$ & $68(19.7)$ & $153(17.3)$ & 96 (12.4) & $<0.001$ \\
\hline Psychologist & $112(5.3)$ & 16 (14.3) & $23(6.7)$ & $42(4.8)$ & $31(4.0)$ & $<0.001$ \\
\hline Dietician & 78 (3.7) & 17 (15.2) & $15(4.3)$ & 34 (3.9) & $12(1.6)$ & $<0.001$ \\
\hline Nurse & $63(3.0)$ & 16 (14.3) & $10(2.9)$ & $25(2.8)$ & $12(1.6)$ & $<0.001$ \\
\hline $\begin{array}{l}\text { Occupational } \\
\text { therapist }\end{array}$ & 25 (1.2) & $2(1.8)$ & $5(1.4)$ & $15(1.7)$ & $3(0.4)$ & 0.080 \\
\hline
\end{tabular}




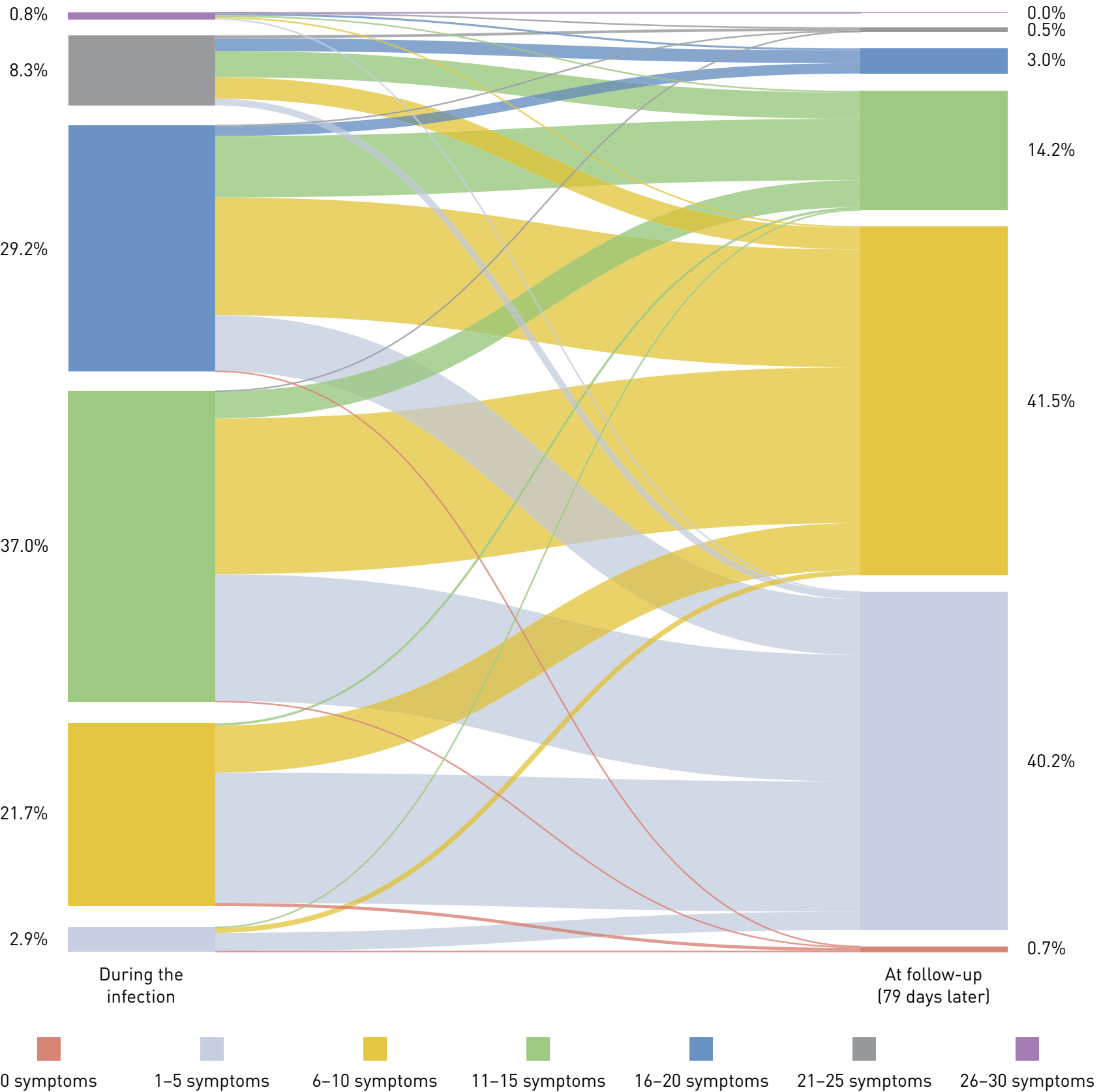

FIGURE 1 Prevalence and change in the total number of symptoms during and 3 months after infection. The width of lines in the figure are proportional to the flow rate.

\section{Discussion}

This is the first study to report that there is only a partial recovery in symptoms about 3 months after the onset of symptoms in a survey of a large sample of previously hospitalised and nonhospitalised patients with confirmed or suspected COVID-19. Indeed, the median number of symptoms is still high 3 months after the onset of symptoms in hospitalised and nonhospitalised patients. Moreover, only a very small proportion of respondents were free of symptoms. This is remarkable for a sample with a median age of 47 years, of which most reported a good health status before the infection and the majority used medical and/or allied health care during/after the infection.

A list of 29 symptoms was completed in a large sample of hospitalised and nonhospitalised patients (and for the nonhospitalised patients: confirmed or suspected COVID-19). This makes the current dataset 
TABLE 2 Symptoms during the infection of the whole sample and stratified for COVID-19 diagnosis

\begin{tabular}{|c|c|c|c|c|c|c|}
\hline & $\begin{array}{l}\text { Whole sample } \\
\qquad(n=2113)\end{array}$ & $\begin{array}{l}\text { Hospitalised } \\
\text { (n=112) }\end{array}$ & $\begin{array}{c}\text { Nonhospitalised (confirmed } \\
\text { COVID-19) }(n=345)\end{array}$ & $\begin{array}{c}\text { Nonhospitalised (symptom-based } \\
\text { COVID-19) }(n=882)\end{array}$ & $\begin{array}{c}\text { Nonhospitalised (suspected } \\
\text { COVID-19) }(n=774)\end{array}$ & p-value \\
\hline Number of symptoms & $14.0(11.0-17.0)$ & $14.0(9.3-17.0)$ & $14.0(11.0-18.0)$ & $14.0(11.0-18.0)$ & $13.0(10.0-17.0)$ & $<0.001$ \\
\hline \multicolumn{7}{|l|}{ Symptoms } \\
\hline Fatigue & 2006 (94.9) & 104 (92.9) & 324 (93.9) & $847(96.0)$ & $731(94.4)$ & 0.226 \\
\hline Dyspnoea & 1892 (89.5) & 100 (89.3) & $300(87.0)$ & 827 (93.8) & 665 [85.9] & $<0.001$ \\
\hline Headache & 1605 (76.0) & 80 (71.4) & $273(79.1)$ & 682 (77.3) & $570(73.6)$ & 0.097 \\
\hline Chest tightness & $1588(75.2)$ & 68 (60.7) & 248 (71.9) & $709(80.4)$ & 563 (72.7) & $<0.001$ \\
\hline Cough & $1438(68.1)$ & 89 (79.5) & $235(68.1)$ & $620(70.3)$ & 494 (63.8) & 0.002 \\
\hline Muscle pain & 1367 (64.7) & $60(53.6)$ & 245 (71.0) & 578 (65.5) & 484 (62.5) & 0.003 \\
\hline Sore throat & 1309 (61.9) & 49 (43.8) & 188 (54.5) & 564 (63.9) & 508 (65.6) & $<0.001$ \\
\hline $\begin{array}{l}\text { Increased body temp. } \\
\left(37.0-37.9^{\circ} \mathrm{C}\right)\end{array}$ & $1293(61.2)$ & 44 (39.3) & 189 (54.8) & 571 (64.7) & 489 (63.2) & $<0.001$ \\
\hline $\begin{array}{l}\text { Pain between } \\
\text { shoulder blades }\end{array}$ & $1289(61.0)$ & 53 (47.3) & 216 (62.6) & 584 (66.2) & 436 (56.3) & $<0.001$ \\
\hline $\begin{array}{l}\text { Pain/burning feeling } \\
\text { in lungs }\end{array}$ & 1279 (60.5) & 53 (47.3) & 178 (51.6) & $587(66.6)$ & 461 (59.6) & $<0.001$ \\
\hline Heart palpitations & 1159 (54.9) & 44 (39.3) & 191 (55.4) & $521(59.1)$ & 403 (52.1) & $<0.001$ \\
\hline $\begin{array}{l}\text { Increased resting } \\
\text { heart rate }\end{array}$ & $1154(54.6)$ & 58 (51.8) & 199 (57.7) & 519 (58.8) & 378 (48.8) & $<0.001$ \\
\hline Dizziness & $1091(51.6)$ & $46(41.1)$ & $171(49.6)$ & $490(55.6)$ & $384(49.6)$ & 0.006 \\
\hline Nose cold & 928 (43.9) & 38 (33.9) & 169 (49.0) & $363(41.2)$ & 358 (46.3) & 0.006 \\
\hline $\begin{array}{l}\text { Burning feeling in the } \\
\text { trachea }\end{array}$ & 927 (43.9) & 37 (33.0) & $121(35.1)$ & 428 (48.5) & $341(44.1)$ & $<0.001$ \\
\hline Fever $\left(\geqslant 38.0^{\circ} \mathrm{C}\right)$ & 903 (42.7) & 94 (83.9) & $178(51.6)$ & $380(43.1)$ & $251(32.4)$ & $<0.001$ \\
\hline Ageusia & 893 (42.3) & 73 (65.2) & 218 (63.2) & $350(39.7)$ & $252(32.6)$ & $<0.001$ \\
\hline Diarrhoea & $869(41.1)$ & 49 (43.8) & 150 (43.5) & $374(42.4)$ & 296 (38.2) & 0.225 \\
\hline Anosmia & 839 (39.7) & $67(59.8)$ & $223(64.6)$ & 308 (34.9) & $241(31.1)$ & $<0.001$ \\
\hline Joint pain & 808 (38.2) & 37 (33.0) & $151(43.8)$ & 340 (38.5) & $280(36.2)$ & 0.066 \\
\hline Nausea & 772 (36.5) & $51(45.5)$ & 124 (35.9) & 341 (38.7) & 256 (33.1) & 0.021 \\
\hline Mucus & 764 (36.2) & 42 (37.5) & $107(31.0)$ & 328 (37.2) & $287(37.1)$ & 0.193 \\
\hline Sneezing & $667(31.6)$ & $27(24.1)$ & 123 (35.7) & $274(31.1)$ & $243(31.4)$ & 0.129 \\
\hline Hot flushes & 548 (25.9) & $18(16.1)$ & $90(26.1)$ & $224(25.4)$ & 216 (27.9) & 0.061 \\
\hline Eye problems & 542 (25.7) & 20 (17.9) & 76 (22.0) & $245(27.8)$ & $201(26.0)$ & 0.045 \\
\hline Ear pain & 459 (21.7) & 12 (10.7) & 74 (21.4) & $210(23.8)$ & $163(21.1)$ & 0.015 \\
\hline $\begin{array}{l}\text { Sudden loss of body } \\
\text { weight }\end{array}$ & 388 (18.4) & 42 (37.5) & 81 (23.5) & 165 (18.7) & 100 (12.9) & $<0.001$ \\
\hline Vomiting & $191(9.0)$ & $24(21.4)$ & $41(11.9)$ & $76(8.6)$ & $50(6.5)$ & $<0.001$ \\
\hline $\begin{array}{l}\text { Red spots on toes/ } \\
\text { feet }\end{array}$ & $118(5.6)$ & $9(8.0)$ & $15(4.3)$ & $50(5.7)$ & $44(5.7)$ & 0.512 \\
\hline Others & $623(29.5)$ & $19(17.0)$ & 87 (25.2) & $284(32.2)$ & $233(30.1)$ & 0.002 \\
\hline
\end{tabular}




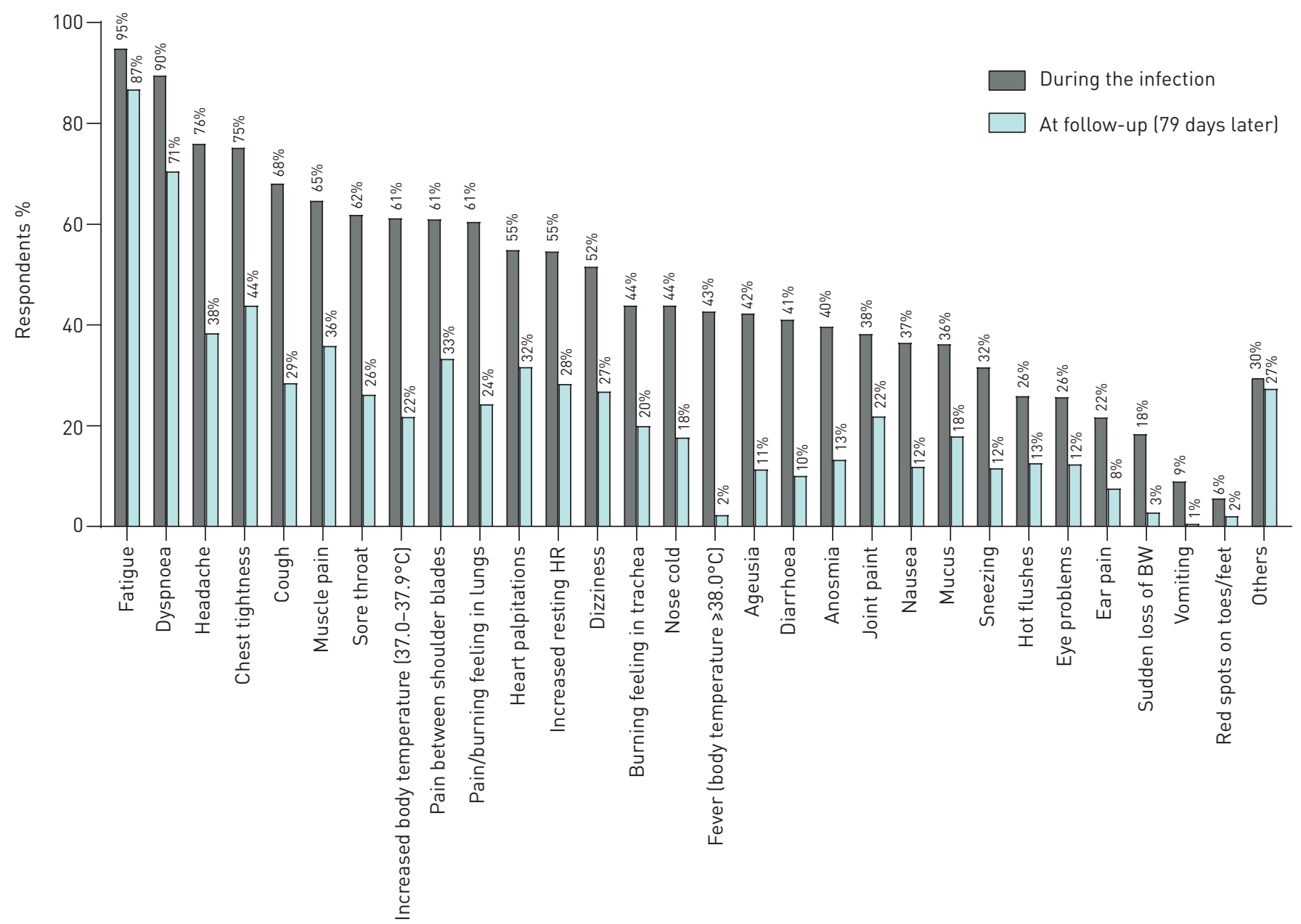

FIGURE 2 Prevalence of symptoms during the infection and at follow-up (79 days later). BW: body weight; HR: heart rate.

unique and allows us to get a first detailed insight into the presence of symptoms about 3 months after the onset of symptoms in previously hospitalised and nonhospitalised patients with COVID-19. A median of six symptoms per patient was reported, of which fatigue and dyspnoea were still very common, also in the nonhospitalised patients. CARF et al. [4] also reported fatigue and dyspnoea about 60 days after the onset of COVID-related symptoms in previously hospitalised patients with COVID-19. This is also in line with findings in other post-viral/infectious syndromes [15-18] and findings from critically ill (non-COVID) patients that have been discharged from the ICU, who still experience a wide array of symptoms months after the hospitalisation, also called the post-ICU syndrome [19].

The current study excluded patients who were admitted to the ICU. Therefore, the current findings are the first indications of a "post-COVID-19 syndrome" in a subgroup of patients, since the symptoms are still present about 3 months after their onset despite receiving usual care. Nonetheless, only $36 \%$ of the variance in symptom burden at follow-up could be explained by the age of the participants, self-reported health status before the onset of symptoms, self-reported pre-existing comorbidities and the number of symptoms during the infection. This provides a clear rationale for additional assessment of the underlying physical, emotional, cognitive and social factors by a multidisciplinary team, which is needed to better understand the persistence of these symptoms and to identify possible traits for pharmacological and nonpharmacological treatment [20,21]. Previously, interventions for chronic fatigue syndrome or post-viral fatigue were developed [22]. Whether or not these interventions are effective post-COVID-19 remains unknown [23]. Moreover, to date it remains unknown whether and to what extent symptom burden post-COVID-19 is comparable with symptom burden in other post(-respiratory)-infectious syndromes. Indeed, it is important to note that in contrast to other post(-respiratory)-infectious syndromes a large array of atypical symptoms such as diarrhoea, heart palpitations, headache, ageusia, anosmia, fever/increased body temperature, are reported months after the infection. 


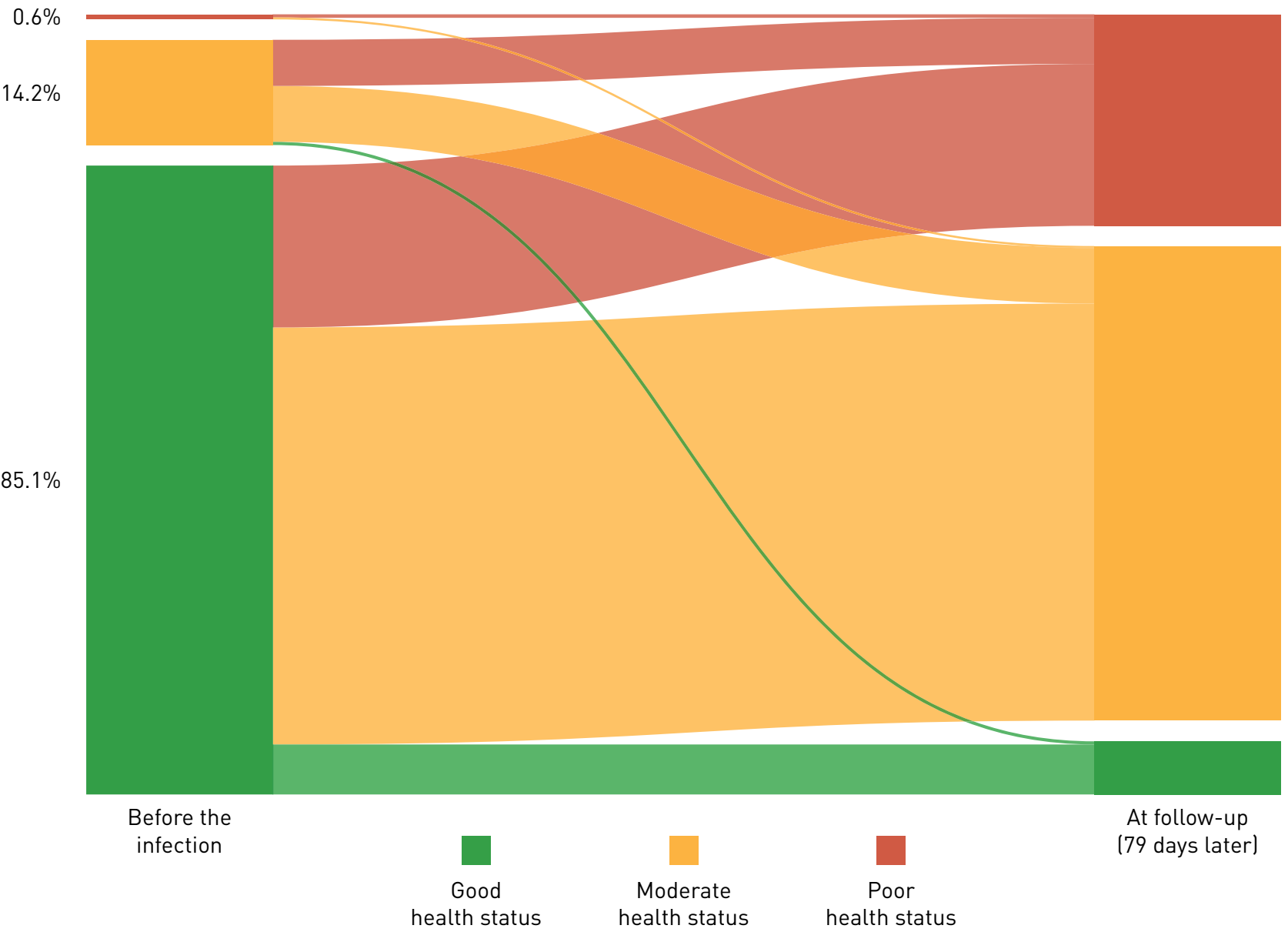

$28.6 \%$

FIGURE 3 Prevalence and change in self-reported health status during and 3 months after the infection. The width of lines in the figure are proportional to the flow rate.

The authors emphasise that readers have to be cautious with the external validity of the current findings, as mostly women responded, whom are more likely to present themselves with symptoms than men [24]. Moreover, only patients with COVID-19 from Facebook groups with persistent symptoms and who registered on www.coronalongplein.nl were included in the study. This most probably resulted in an overestimation of the true symptom burden in the nonhospitalised group of patients with COVID-19. Then again, the hospitalised group was older, had more comorbidities, higher BMI and a higher proportion of males than the nonhospitalised groups, which is in line with previous findings [25]. So, the current study should mostly be used to create broad awareness amongst healthcare professionals, employers, insurers and society at large about the fact that there are most probably thousands of patients with so-called "mild" COVID-19 who do not all recover fully about 3 months following the onset of symptoms. Getting these issues out into the open is an important first step as patients with "mild" COVID-19 got little guidance and were often abandoned to their fate in comparison to hospitalised patients. By that, patients will feel understood and get recognition (by friends, relatives, employers and healthcare professionals) on the one hand, and healthcare professionals will be informed about the large heterogeneity and possible long-term presence of symptoms associated to this novel virus which is also prevalent in patients with "mild" COVID-19, on the other hand. The size of this persistent symptomatic group of "mild" COVID-19 remains to be determined, as well as their symptom trajectory over time. In addition, the current study indicates that in a subgroup of patients with "severe" COVID-19 (e.g. those who were hospitalised) also a symptom burden persists in the months after the onset of symptoms this is in line with recent findings in hospitalised patients [4]. Taken the abovementioned limitations into consideration, the current data are still eye-opening, as most respondents stated that their general health was good before the infection, and now this is only true for a minority. To conclude, the current results emphasise the presence of multiple symptoms and, in turn, unmet healthcare needs of this large sample of 
hospitalised and nonhospitalised patients with confirmed or suspected COVID-19 about 3 months after the infection. The phenomenon that symptoms still persist months after the infection suggests the presence of a "post-COVID-19 syndrome".

Acknowledgements: The research team acknowledges the valuable input from the patient representatives to develop the survey and the technical support by Martijn Briejer and Oscar Wagemakers (ASolutions BV, Capelle an den IJssel, the Netherlands).

Author contributions: Y.M.J. Goërtz and M. Van Herck were co-first authors. Y.M.J. Goërtz, M. Van Herck, J.M. Delbressine, A.W. Vaes, R. Meys, F.V.C. Machado and S. Houben-Wilke were responsible for the data collection. M.A. Spruit is the principal investigator of this trial. Y.M.J. Goërtz, M. Van Herck, D.J.A. Janssen and M.A. Spruit drafted the manuscript. All authors critically reviewed and revised the manuscript.

Conflict of interest: Y.M.J. Goërtz has nothing to disclose. M. Van Herck has nothing to disclose. J.M. Delbressine has nothing to disclose. A.W. Vaes has nothing to disclose. R. Meys has nothing to disclose. F.V.C. Machado has nothing to disclose. S. Houben-Wilke has nothing to disclose. C. Burtin has nothing to disclose. R. Posthuma has nothing to disclose. F.M.E. Franssen reports personal fees from GlaxoSmithKline, Chiesi and Boehringer Inghelheim, grants and personal fees from AstraZeneca and Novartis, and personal fees from TEVA, outside the submitted work. N. van Loon has nothing to disclose. B. Hajian has nothing to disclose. Y. Spies has nothing to disclose. H. Vijlbrief has nothing to disclose. A.J. van 't Hul has nothing to disclose. D.J.A. Janssen reports speaker fees from Novartis, Boehringer Ingelheim and AstraZeneca, outside the submitted work. M.A. Spruit reports grants from Lung Foundation Netherlands and Stichting Astma Bestrijding, and grants and personal fees from Boehringer Ingelheim and AstraZeneca, outside the submitted work.

Support statement: The scientific work of Y.M.J. Goërtz is financially supported by Lung Foundation Netherlands grant 4.1.16.085, F.V.C. Machado is financially supported by European Union grant ZonMw ERACoSysMed 90030355 and R. Meys is financially supported by Lung Foundation Netherlands grant 5.1.18.232. Funding information for this article has been deposited with the Crossref Funder Registry.

\section{References}

1 Johns Hopkins University \& Medicine. Coronavirus Resource Center. https://coronavirus.jhu.edu/ Date last updated: 8 July, 2020. Date last accessed: 9 July, 2020.

2 Li LQ, Huang T, Wang YQ, et al. COVID-19 patients' clinical characteristics, discharge rate, and fatality rate of meta-analysis. J Med Virol 2020; 92: 577-583.

3 Guan WJ, Ni ZY, Hu Y, et al. Clinical characteristics of coronavirus disease 2019 in China. N Engl J Med 2020; 382: $1708-1720$.

4 Carfi A, Bernabei R, Landi F, et al. Persistent symptoms in patients after acute COVID-19. JAMA 2020; 324: 603-605.

5 Li R, Pei S, Chen B, et al. Substantial undocumented infection facilitates the rapid dissemination of novel coronavirus (SARS-CoV-2). Science 2020; 368: 489-493.

6 Stringhini S, Wisniak A, Piumatti G, et al. Seroprevalence of anti-SARS-CoV-2 IgG antibodies in Geneva, Switzerland (SEROCoV-POP): a population-based study. Lancet 2020; 396: 313-319.

7 Centers for Disease Control and Prevention. Interim Guidance for Implementing Home Care of People Not Requiring Hospitalization for Coronavirus Disease 2019 (COVID-19). www.cdc.gov/coronavirus/2019-ncov/ downloads/guidance-home-care.pdf Date last updated: 28 June, 2020. Date last accessed: 9 July, 2020.

8 Gandhi RT, Lynch JB, Del Rio C. Mild or moderate COVID-19. N Engl J Med 2020; in press [https://doi.org/10 1056/NEJMcp2009249].

9 Garner P. The BMJ opinion: COVID-19 and fatigue - a game of snakes and ladders. https:/blogs.bmj.com/bmj/ 2020/05/19/paul-garner-covid-19-and-fatigue-a-game-of-snakes-and-ladders/ Date last updated: 19 May, 2020. Date last accessed: 9 July, 2020.

10 The Atlantic. COVID-19 can last for several months: the disease's "long-haulers" have endured relentless waves of debilitating symptoms - and disbelief from doctors and friends. Date last updated: 4 June, 2020. Date last accessed: 9 July, 2020. www.theatlantic.com/health/archive/2020/06/covid-19-coronavirus-longterm-symptomsmonths/612679/.

11 Public Facebook Group: Corona ervaringen en langdurige klachten! 2020. www.facebook.com/groups/ 236723204035929.9 Date last updated: 9 July, 2020. Date last accessed: 9 July, 2020.

12 Public Facebook Group: Corona patiënten met langdurige klachten (Vlaanderen). 2020. www.facebook.com/ groups/241043323639334 Date last updated: 9 July, 2020. Date last accessed: 9 July, 2020.

13 Docherty AB, Harrison EM, Green CA, et al. Features of 20133 UK patients in hospital with COVID-19 using the ISARIC WHO clinical characterisation protocol: prospective observational cohort study. BMJ 2020; 369: m1985.

14 Lechien JR, Chiesa-Estomba CM, Place S, et al. Clinical and epidemiological characteristics of 1420 European patients with mild-to-moderate coronavirus disease 2019. J Intern Med 2020; 288: 335-344.

15 Lam MH, Wing YK, Yu MW, et al. Mental morbidities and chronic fatigue in severe acute respiratory syndrome survivors: long-term follow-up. Arch Intern Med 2009; 169: 2142-2147.

16 Moldofsky H, Patcai J. Chronic widespread musculoskeletal pain, fatigue, depression and disordered sleep in chronic post-SARS syndrome; a case-controlled study. BMC Neurol 2011; 11: 37.

17 Schanke AK, Stanghelle JK. Fatigue in polio survivors. Spinal Cord 2001; 39: 243-251.

18 Voss JG. Predictors and correlates of fatigue in HIV/AIDS. J Pain Symptom Manage 2005; 29: 173-184

19 Svenningsen H, Langhorn L, Ågård AS, et al. Post-ICU symptoms, consequences, and follow-up: an integrative review. Nurs Crit Care 2017; 22: 212-220.

20 Spruit MA, Singh SJ, Garvey C, et al. An official American Thoracic Society/European Respiratory Society statement: key concepts and advances in pulmonary rehabilitation. Am J Respir Crit Care Med 2013; 188: e13-e64. 
21 Polastri M, Nava S, Clini E, et al. COVID-19 and pulmonary rehabilitation: preparing for phase three. Eur Respir J 2020; 55: 2001822

22 Rimes KA, Chalder T. Treatments for chronic fatigue syndrome. Occup Med (Lond) 2005; 55: 32-39.

23 Torjesen I. NICE cautions against using graded exercise therapy for patients recovering from covid-19. BMJ 2020; 370: $\mathrm{m} 2912$.

24 Bardel A, Wallander MA, Wallman T, et al. Age and sex related self-reported symptoms in a general population across 30 years: patterns of reporting and secular trend. PLoS ONE 2019; 14: e0211532.

25 Petrilli CM, Jones SA, Yang J, et al. Factors associated with hospital admission and critical illness among 5279 people with coronavirus disease 2019 in New York City: prospective cohort study. BMJ 2020; 369: m1966. 